\title{
DERECHO PENAL Y GÉNERO
}

\section{Camilo Sampedro Arrubla*}

Resumen: La violencia de género es un fenómeno innegable, como lo es el deber del Estado de ocuparse de su prevención, mediante políticas públicas idóneas y razonables; si la política criminal y la ley penal hacen parte de la estrategia estatal contra la violencia originada contra las mujeres, su uso debe obedecer a los mismos criterios como única manera de afirmar su legitimidad; en consecuencia, la política criminal debe procurar medidas menos costosas que la criminalización de conductas y solo llegar a ellas honrando la subsidiariedad del Derecho penal y su uso como última razón de Estado. Si resulta inevitable y se decide acudir al Derecho penal en el contexto de violencia de género, debe tenerse el cuidado de no discriminar negativamente en aras de hacerlo positivamente, lesionando el principio de igualdad de la ley penal.

Palabras clave: Violencia de género, Violencia contra las mujeres, Política criminal y Derecho penal de género, Discriminación positiva, Acciones afirmativas, Derecho penal subsidiario, Última razón de Estado y principio de igualdad.

\footnotetext{
Abogado de la Universidad Externado de Colombia. Especialista en Ciencias Penales y Criminológicas de la Universidad Externado de Colombia. Estudios de Maestría en Ciencias Penales y Criminológicas de la Universidad Externado de Colombia. Candidato al título de Doctor en Derecho de la Universidad Externado de Colombia. Profesor titular del Departamento de Derecho Penal de la Universidad Externado de Colombia en pregrado y postgrado (especialización y maestría). Bogotá, Colombia.E mail: camilo.sampedro@uexternado.edu.co. Fecha de recepción: 18 de enero de 2017. Fecha de aceptación: 15 de enero de 2018. Para citar el artículo: CAmilo SAMPEdro ArRubla. "Derecho penal y género", Revista Derecho Penal y Criminología, Vol. 38, n. ${ }^{\circ}$ 105, julio-diciembre de 2017, Bogotá, Universidad Externado de Colombia, pp. 207-225.

DOI: https://doi.org/10.18601/ 01210483.v38n105.09
} 


\title{
CRIMINAL LAW AND GENDER
}

\begin{abstract}
Gender violence is an undeniable phenomenon, as is the duty of the State to deal with its prevention, through appropriate and reasonable public policies; if criminal policy and criminal law are part of the state's strategy against violence against women, its use must obey the same criteria as the only way to affirm its legitimacy; consequently, criminal policy should seek less costly measures than the criminalization of behaviors and only reach them by honoring the subsidiarity of criminal law and its use as a last state reason. If it is inevitable and it is decided to resort to criminal law in the context of gender violence, care must be taken not to discriminate negatively in order to do so positively, thus harming the principle of equality of criminal law.
\end{abstract}

KEYWORDS: gender violence, violence against women, criminal policy and gender criminal law, positive discrimination, affirmative actions, subsidiary criminal law, last reason of state and principle of equality.

\section{INTRODUCCIÓN Y PRESUPUESTOS}

1.- La realidad colombiana, aunque no es exclusiva de nuestro país, muestra de manera inocultable, incluso con cifras $^{1-2}$, los altos niveles de violencia contra las mujeres. Negar que las mujeres son víctimas de violencia sería tan necio como negar que también lo son los niños, los hombres, los ancianos, los indígenas, los extranjeros, los afrocolombianos, los homosexuales, etc., en fin, que todos somos reales o potenciales víctimas de la violencia en Colombia y que, así como todos lo somos individualmente, también cada uno de los grupos poblacionales de nuestro país. Tampoco podría negar que la mujer es sujeto especialmente vulnerable frente a la violencia y que ello se hace más evidente en ciertos contextos como son las relaciones de pareja ${ }^{3}$ o el conflicto armado ${ }^{4}$.

1 Corporación Sisma Mujer. "Comportamiento de as violencias contra las niñas y mujeres en Colombia a partir del Informe Forensis del Instituto Colombiano de Medicina Legal “ Julio 18 de 2017.

2 Informe Forensis 2016 Instituto Colombiano de Medicina Legal Grupo Centro de referencia Nacional sobre la violencia Primera edición. Bogotá, D.C. Junio, 2017

3 De 2007 a 2016 se registran 52.284 casis de violencia en el contexto de las relaciones de pareja. Y de ellos, en el 86 \% la víctima es la mujer. Informe Forensis 2016 Instituto Colombiano de Medicina Legal Grupo Centro de referencia Nacional sobre la violencia Primera edición. Bogotá, D.C. Junio, 2017 , p. 306.

4 Cardona Gómez, Gloria del Pilar.; Franco Cian, Laura.; Aldana Nope, Adriana Carolina. "Los rostros de las mujeres víctimas del conflicto armado en Colombia: diferentes formas de violencia de género", Universidad El Bosque Colombia. En: Informe Forensis 2016 Instituto Colombiano de Medicina Legal Grupo Centro de referencia Nacional sobre la violencia Primera edición. Bogotá, D.C. Junio, 2017, p. 624. 
No es ni será nunca mi propósito negar notorias verdades. Por el contrario, soy un absoluto combatiente en contra de la violencia en contra de cualquier colectivo o cualquier persona. Precisamente por ello me declaro promotor del derecho del otro, del de al lado, del de todos por igual aun cuando diferentes.

Como consecuencia de lo dicho debo partir del supuesto, base de mi postura sin ningún tipo de motivación oculta, según el cual la mujer en Colombia es víctima de la violencia, particularmente en el contexto del género y que corresponde a la comunidad internacional y al Estado procurar las medidas para que ello deje de ser así ${ }^{5}$. De hecho, lo que resulta demostrativo de la desafortunada realidad, así se reconoce en instrumentos internacionales como la Convención Interamericana para prevenir, sancionar y erradicar la violencia contra la mujer "Convención de Belem do Pará"6, la Convención sobre la eliminación de todas las formas de discriminación contra la mujer ${ }^{7}$ y su protocolo, el Estatuto de Roma ${ }^{8}$ y sus reglas, etc., a más de las normativas constitucionales internas que, como la nuestra, dan valor superior a la internacional de derechos humanos, como es el caso de aquella que se ocupa de la prevención y erradicación de la violencia contra las mujeres.

Pero, en mi concepto desde luego, esa realidad es una cosa y otra bien distinta es que ella justifique, sin más y sin límites, la discriminación positiva de las mujeres bajo la justificación de la histórica dominación masculina, redundando en el menor aprecio de la violencia de la que también son víctimas otros sectores poblacionales históricamente considerados dominados o no, que aun siéndolo o habiéndolo sido, no por ello escapan de su condición de víctimas potenciales cuando no reales y si se quiere también, en condición de especial situación de vulnerabilidad.

¿Cuál ha de ser el compromiso de un Estado serio en materia de violencia de género? ¿La discriminación solo simbólica, irracional, errática, ilógica, asistémica, en fin, sin límites o a toda costa, incluyendo aquella que incide en lo penal? o ¿La atención eficaz, racional, sistemática, lógica y limitada, llegando, de ser necesario, a hacerse a través del derecho penal pero entendido como última razón de Estado, subsidiario e incluso simbólico, esto último siempre que se alcancen los demás fines de la pena?

Aun si nos mantuviéramos al margen de los compromisos internacionales, un Estado como el nuestro se debe ocupar de la prevención de todo tipo de violencia, incluida la originada en razones de género y debe implementar todas las medidas necesarias para

5 Arocena, Gustavo y Cesano, José. “El Delito de Feminicidio” Aspectos político criminales y análisis dogmático jurídico. Ed. BdeF Montevideo, Uruguay, 2013, p. 16

6 “Convención para Prevenir, Sancionar y Erradicar la Violencia contra la Mujer” Adoptada por la Ley 248 de 1995

7 CEDAW 1979. Adoptada por la Ley 51 de 1981

8 Naciones Unidas. Ley 742 de 2002. 
ello 9 . La pregunta que debemos hacernos, no es la que permite hacer tal afirmación en tanto obvia, la que corresponde hacer es la que interesa al título de este artículo y sus motivaciones, y es si el Estado debe y en qué medida o de qué manera, ocuparse de ello a través de la sumatoria entre Derecho penal y discriminación positiva.

2.- El Derecho penal de género no se limita al feminicidio como agravante o como delito autónomo, ni siquiera al Derecho penal especial, ni, incluso, al Código Penal; tampoco se limita a la consideración de la mujer como víctima, también debe considerarla como victimaria y en todo momento del sistema penal, tanto en el proceso legislativo (especialmente desde la tipificación) como en el momento judicial y de ejecución de la sentencia. En efecto, y solo para mencionar algunos tópicos, hay o podría haber justificación razonable de la consideración incidente del género mujer en el feminicidio, en los delitos contra la libertad sexual, en el aborto como víctima y como victimario, en el principio de oportunidad, en las terminaciones anticipadas del proceso, en las condiciones en que se presta el tratamiento penitenciario a los hombres agresores y a las mujeres condenadas por cualquier delito, etc., etc.

3.- Permítanme antes de continuar, establecer otro presupuesto: podríamos entender la diferencia de género en sentido amplio como toda diferencia entre hombres y mujeres. Sin embargo, creo que solo es correcto entenderla en un sentido restrictivo, asumiendo que una es la diferencia en el trato a los seres humanos en razón del género como escenario de acciones afirmativas como la discriminación en favor y otra la diferencia que surge del sexo y sus particularidades. Me explico: un asunto es que, refiriéndome a hombres y mujeres, se tomen medidas que pretendan la igualación entre dos sectores de población cuando uno se encuentra en especial situación de vulnerabilidad por dominación histórica -lo que podría motivar una justificación razonable de la discriminación positiva como acción afirmativa a favor de la mujer-, como por ejemplo el lenguaje incluyente, la ley de cuotas, los transportes públicos exclusivos, el acceso a servicio público preferencial, etc. -las que no comparto en principio y por principio, por muchas razones que van desde el respeto por la mujer misma hasta la ética y la estética-, y otra bien distinta el trato diferencial originado en las condiciones físicas particulares de un sector de la población, que motivan políticas públicas diferenciadas -incluso en materia de política criminal ${ }^{10}$ - pero que no se adoptan con el ánimo de lograr igualar (en términos de nivelación) a quienes deberían ser iguales, sino producto pacífico del reconocimiento de la diferencia, siempre apreciable.

Con un ejemplo seguro se transmite mejor. Resulta innegable la razonabilidad constitucional de exigir (hablando de lo penal), por ejemplo, guarderías en las cárceles de

9 Constitución Política de Colombia, artículo 13.

10 Comisión Asesora de Política Criminal. Informe Final. Diagnósticos y Propuesta de Lineamientos de política criminal para el Estado colombiano, Ministerio de Justicia y el Derecho Colombia. Agencia Presidencial de Cooperación Internacional de Colombia APC. Unión Europea, Bogotá, junio de 2012. 
mujeres o cualquier otra medida en consideración a su calidad de madres en reclusión. Nadie dudaría, con una propuesta así, al afirmar las bondades de la discriminación positiva en pro de las mujeres al interior del sistema penal. Sin embargo, aunque el planteamiento es seductor, resulta equivocado para referirse a la discriminación positiva en punto al género, porque este caso, como el del ginecólogo en los centros de reclusión femeninos, el psicólogo en el de menores, etc. no son acciones afirmativas que discriminan positivamente el sector poblacional beneficiado con ellas para corregir patrones culturales disfuncionales, sino medidas adoptadas en razón de la diferencia fisiológica que nunca se zanjará. Por ello precisamente hablo de "igualación", porque solo las medidas que pretenden acabar con la diferencia por el género y que por ende pueden acabarla obteniendo la igualdad, constituyen discriminación positiva como acción afirmativa, las demás son políticas de reconocimiento de la diferencia.

Desde luego ya en ámbito exclusivo del Derecho penal también se puede dar la confusión, por lo que resulta aplicable la aclaración con la que se parte como presupuesto: una cosa es la consagración de delitos en consideración al género (se esté o no de acuerdo) como el caso del feminicidio y otra bien distinta la consagración de delitos en consideración a la diferencia inevitable como el aborto preterintencional en el que la víctima siempre será una mujer, no por consideraciones de género sino por diferencias biológicas.

\section{POLÍTICA CRIMINAL Y GÉNERO}

Permítanme hacer mías las palabras de la Informe final de la Comisión Asesora de Política Criminal "Diagnóstico y propuesta de lineamientos de política criminal para el Estado Colombiano” de junio de 2012:

"La Comisión tiene claro que los enfoques diferenciales son diversos e incluyen la perspectiva de género, étnica, por edad, por vulneración económica, por personas con discapacidad, etc.

La incorporación del enfoque diferencial de género en la política criminal es importante como una forma de visibilizar las situaciones de discriminación de las mujeres y una posibilidad de implementar las medidas correspondientes para prevenir y contribuir a la erradicación de esa situación discriminatoria"11

11 Comisión Asesora de Política Criminal. Informe Final. Diagnósticos y Propuesta de Lineamientos de política criminal para el Estado colombiano, Ministerio de Justicia y el Derecho Colombia. Agencia Presidencial de Cooperación Internacional de Colombia APC. Unión Europea, Bogotá, junio de 2012, p. 70 . 
Sin embargo, sigue:

El derecho penal se sigue viendo como una herramienta necesaria y reclamada por muchos sectores de las organizaciones de mujeres, que consideran que la tipificación de algunas conductas como delitos contribuye a una mayor protección de sus derechos. En este contexto, se ubica la figura del feminicidio, ... es fundamental complementarla con otras medidas tales como las estadísticas y los registros de estos hechos ...y que el tema se vincule a los debates existentes sobre seguridad ciudadana. ${ }^{12}$

En efecto, aun cuando en el informe citado se formulan recomendaciones que no necesariamente se fundamentan en el género sino en las diferencias inigualables entre unos y otros, lo cierto es que en él se concluye con razón que, aunque la política criminal debe ser entendida y estructurada como una política pública relacionada con el Derecho penal, aquella no se agota en este.

La política criminal también debe atender los criterios de subsidiariedad ${ }^{13}$ del Derecho penal. En efecto, creo que una correcta política pública frente al delito, debe dirigirse en primer lugar a la implementación de todas las medidas posibles distintas (menos drásticas) a la criminalización de conductas para su evitación y no, por el contrario, que acuda a ella como prima ratio. En este sentido solo se debe hacer uso de la tipificación de conductas cuando esté demostrado, por un lado, que las demás medidas de política pública, menos drásticas, habiendo sido implementadas correctamente, no han resultado suficientes y que la criminalización, por otro, sí lo será ${ }^{14}$. De otra manera no se legitima el Derecho penal, si no es por un puro simbolismo atado a sus consecuencias ${ }^{15}$.

Pero valerse del sistema penal no necesariamente conduce a la criminalización. El Estado puede valerse de él accionándolo de la mano de otras políticas públicas, regulando, por ejemplo, la diferencia en el acceso a la justicia condicionada al género; la consolidación de información respecto de los hechos acaecidos en Colombia y en sus regiones, etc., que permitan análisis empíricos que conduzcan a medidas distintas a lo penal o, mejor, que eviten la competencia del Derecho penal. No podemos olvidar que la política criminal es una política pública y que como tal debe ir dirigida al logro de los fines estatales frente a los que el Derecho penal solo es un medio y no un fin; un medio muy costoso, el más costoso y por ende supletorio de cualquier otro.

12 Ídem, p. 71.

13 El carácter subsidiario del derecho penal supone que solo es competente en subsidio de las demás herramientas jurídicas y no jurídicas idóneas para la finalidad propuesta. Ello supone entonces que también son preferibles las medidas de política criminal ajenas al Derecho penal.

14 Arocena, Gustavo y Cesano, José, El Delito de Feminicidio. Aspectos político criminales y análisis dogmático jurídico. Ed. BdeF Montevideo, Uruguay, 2013, p. 59.

15 Ídem, p. 58. 
Ahora bien, entendiendo por discriminación positiva aquella política, pública o no, que pretende diferenciar el tratamiento que se les da a dos grupos poblacionales para privilegiar a aquel que está o ha estado en situación de desventaja injusta respecto del otro. Es discriminación porque mejora solo a uno de los dos grupos y es positiva porque su propósito no es desfavorecer al históricamente privilegiado, sino mejorar al otro en aras de compensación, de equilibrio, de obtener o alcanzar la igualdad, es decir es una medida o acción promocional o de impulso.

Creo que nadie podría discutir la bondad pretendida por una discriminación tal (por ejemplo, desde la ley o no, en acceso a servicios, aplicación de cargas impositivas, acceso a puestos públicos, lenguaje incluyente, etc.)

Sin embargo, la pregunta es si la obligación constitucional e internacional de atención especial de los reconocidos como en situación de vulnerabilidad o por lo menos como colectivo acreedor de acciones afirmativas, es una labor que debe cumplirse a través del Derecho penal, o si la política criminal por serlo solo actúa a través del Derecho penal. En otras palabras, y en concreto para lo que nos interesa, me pregunto (progresivamente) si el deber constitucional de implementar políticas públicas para quienes están en situación de desigualdad opera automáticamente para las mujeres; de ser así, si de ello debe ocuparse la política criminal; de ser afirmativa la respuesta, si debe hacerse a través del Derecho penal y por último, de ser la respuesta la competencia penal, me pregunto si debe ser a través de la tipificación de conductas que repriman los comportamientos de quienes atenten contra bienes jurídicos en razón del género de la víctima o promueven peyorativamente la diferencia o si, por el contrario, puede o debe hacerse a través de medidas penales distintas.

En este punto debo ocuparme de las preguntas formuladas en tres bloques, aunque por espacio, pero fundamentalmente por el límite del tema propuesto para este artículo, solo me referiré, con algo de extensión, al directamente relacionado con el Derecho penal y la tipificación de las conductas. De los otros dos, alguna mínima reflexión, más bien provocadora.

Así pues, ¿Opera la obligación de discriminación positiva, o por lo menos de acciones afirmativas para las mujeres, automáticamente, por serlo?

Aunque tiempo atrás la jurisprudencia se ha pronunciando sobre este tópico y la Corte Constitucional, en momento trascendente de nuestra evolución constitucional, generó importantes pronunciamientos teóricos que se mantienen ${ }^{16}$, no parece recomendable ofender algún sector de la población (aun tradicional o históricamente discrimina-

16 Ver entre otras la sentencias de la Corte Constitucional C098 y 410 de 1994, C481 de 1998, C112 y C371 de 2000. 
do), como el femenino para el tema que nos ocupa, con absurdos paternalismos ${ }^{17}$ que, en cambio de igualar, resaltan la diferencia y la institucionalizan. Tampoco lo es la inclusión de un sector de la población de especial atención o de situación que justifique su trato diferencial, en políticas referentes a aquello en lo que no son diferentes. Pero si la decisión es hacerlo, como por ejemplo en aquellos casos en que ser mujer le da una ventaja comparativa en el acceso a ciertos cargos públicos (aun cuando la ley de cuotas no se estructura con base en ventajas competitivas sino por porcentajes de plazas), un juicio de proporcionalidad no operaría en abstracto sino en concreto, por lo que la implementación de la discriminación positiva no podría ser automática. Piensen por ejemplo en Tibasosa, la población colombiana que durante 26 años fue gobernada casi exclusivamente por mujeres porque (aun sin ley de cuotas) la inmensa mayoría de las plazas públicas, y no solo de la alcaldía, eran ocupadas con excelencia, por mujeres. ¿Debería operar algún tipo de acción afirmativa o discriminación positiva a favor de la mujer a pesar de la situación?

En segundo lugar, aun cuando se dijera sí a la discriminación automática, corresponde preguntarse si tal discriminación debe hacerse a través de la política criminal. Aquí la respuesta puede ser afirmativa, lo que no significa que deba hacerse a través del Derecho penal como su instrumento, en tanto que aquella, preferentemente, debe ocuparse de todo aquello que sea competencia del Derecho penal con todo aquello que no lo sea. Sin más, una política criminal ideal es la que hace innecesario acudir al Derecho penal porque a través de medidas distintas a la criminalización o a la penalización, se logra la evitación o el manejo del fenómeno delictual.

No debe olvidarse, y por el contrario es importante recordar, que el delito no es un problema legal, que en realidad es un problema social y como tal no puede tener la solución en la ley, sino allí en donde la tienen los problemas sociales (en la antropología, el trabajo social, la psicología, la sociología, etc.), no sé en dónde, pero lejos sí del violento derecho penal.

Ya respecto del Derecho penal como instrumento de acción afirmativa a favor de poblaciones en situación reconocida de especial vulnerabilidad, pareciera que se puede afirmar el escaso aporte del Derecho penal sin sustento en términos de prevención ${ }^{18}$, para lo que me basta observar la relación directa que hay entre populismo punitivo e índices de criminalidad ${ }^{19}$-aunque, debo reconocer también que aunque no es difícil comprobar empíricamente que el delito aumenta a pesar del incremento punitivo,

17 Ver: LAURenzo, PATricia, La Violencia de género en el derecho penal: un ejemplo de paternalismo punitivo en Género, Violencia y Derecho, Ed. Del Puerto, Buenos Aires, Argentina, 2009.

18 Maqueda, María Luisa, ¿Es la estrategia penal una solución a la violencia contra las mujeres? Algunas respuestas desde un discurso feminista crítico, Ed. Del Puerto. Buenos Aires, Argentina, 2009 , p. 291.

19 Comisión Asesora de Política Criminal, Informe Final. Diagnósticos y Propuesta de Lineamientos de política criminal para el Estado colombiano, Ministerio de Justicia y el Derecho Colombia, Agencia 
siempre resultará imposible saber cuántos sujetos se abstuvieron de cometer un delito gracias a la consagración de él en la ley penal o al aumento de las penas para ese determinado comportamiento-. En cualquier caso, lo que me quiero cuestionar es si es verdad que con el derecho penal o mejor, a través de la tipificación de conductas o el aumento de penas en los eventos de violencia contra las mujeres, se privilegia o es posible discriminarlas positivamente, más allá del puro simbolismo del Derecho penal. También, por supuesto, si el Derecho penal puede hacer consideraciones, distintas a la consagración de conductas punibles, en aras de discriminación positiva. ${ }^{20}$

\section{DERECHO PENAL Y GÉNERO}

\section{Derecho penal sustancial y discriminación positiva}

Si el Derecho penal es más que un catalogo de penas tendríamos que afirmar que él, o mejor el sistema de Derecho penal, está condicionado por una perspectiva de género. Ello ocurre en dos dimensiones. En la consideración de la mujer como victimaria y en su consideración como víctima.

Pero que ello sea así, no me impide preguntar si el Derecho penal debe discriminar positivamente y si debe, particularmente, hacer discriminaciones positivas respecto del género.

Habiendo delimitado o distinguido lo que en nuestro concepto es discriminación positiva como acción afirmativa y trato diferencial en razón de la diferencia, me resulta imperioso recordar, como es de todos conocido, que el Derecho penal adolece de varios problemas. Ya desde el momento legislativo se identifican algunos, de los cuales hago mención obligada de dos que se relacionan con el tema que nos propusimos. Me refiero a la función simbólica del Derecho penal, entendida aisladamente, y a la tipificación casuística, que, en muchas ocasiones, como en esta, van cogidas de la mano.

En efecto, se parte de la idea de la pena en su momento legal cumple una función preventiva general, en tanto que, suponiendo el conocimiento de la ley por todos los destinatarios, ellos se abstendrían de cometer el delito para el cual se asocia. En la misma línea, podría pensarse que elaborando una definición típica concreta a la cual se asocie la pena, tendrá más efectividad el llamado de la prevención general.

Presidencial de Cooperación Internacional de Colombia APC, Unión Europea, Bogotá, junio de 2012, pp. 33 y 34 .

20 Ver: La Violencia de género en el derecho penal: un ejemplo de paternalismo punitivo en Género, Violencia y Derecho, Ed. Del Puerto, Buenos Aires, Argentina, 2009. 
Así las cosas, se diría, si se logra una tipicidad específica con una pena especial que haga que el tipo resalte entre los demás, habrá prevención y por ende evitación.

Otra vez: estoy convencido que, como problema social, para la violencia de género debemos buscar la solución en otro lugar, distinto a la ley penal. Podremos llegar al momento en que reconocemos que no hay nada más que hacer que perseguir con el Derecho penal al agresor, pero para ese momento habrá que haberse honrado el principio de política criminal según el cual el legislador deberá contar con el material que le permita sustentar, no solamente que las medidas existentes al momento de la nueva tipicidad no son suficientes, sino que las que se proponen si los son, por idóneas, en términos de prevención ${ }^{21}$. De lo contrario estaremos en presencia de un Derecho penal puramente simbólico, muy conveniente para quienes buscan impresionar al grupo poblacional a favor de quien se dirigen, pero finalmente perjudicial, no solo por la defraudación misma respecto de la ley y la administración de justica, sino además por la pérdida de confianza en el sistema del que se siente una desprotección tal que dimensiona el problema.

No. Creo que el Derecho penal, de aceptarse su utilidad, no puede llegar a tipificar solo con pretensión de simbolismo y reformando asistemáticamente el código de las penas, como ocurrió con la tipicidad del feminicidio en Colombia, un paradigmático caso en el que respondiendo a presiones sectoriales y a desafortunadísimas coyunturas (la mujeres víctimas, las quemas con ácido, la violencia intrafamiliar, etc.) se prefirió la tipificación como delito autónomo del homicidio, incluso agravado, incrementando la pena sin sustento que permitiera afirmar no solo la no efectividad de la tipificación agravada y derogada con el feminicidio (como recomendación de política criminal), sino la efectividad esperada de esta.

Con algunas estadísticas se justifica todo y más, la inefectividad de un tipo penal como el del homicidio agravado por la calidad mujer de la víctima, en tanto que el delito a pesar de su consagración especial como tal se incrementa. En efecto, resultaría fácil y seductor, aunque realmente constituya un sofisma, afirmar que a pesar de la consagración legal especial del homicidio agravado en razón del género y del aumento en la pena, este delito se presenta cada día con mayor frecuencia, con lo que se justificaría la reforma en tanto evidenciado que la tipificación del delito básico o con la agravante no resulta suficiente.

Pero mientras el homicidio en razón del género se combata con medidas o políticas que ataquen al violento y no la violencia, con ello solo se inocuizará, de capturar-

21 Comisión Asesora de Política Criminal, Informe Final. Diagnósticos y Propuesta de Lineamientos de política criminal para el Estado colombiano, Ministerio de Justicia y el Derecho Colombia. Agencia Presidencial de Cooperación Internacional de Colombia APC, Unión Europea, Bogotá, junio de 2012, pp. 33 y 64 . 
se, a quien realiza un acto y solo por un tiempo, por lo que la Ley 1761 de 2015 y cualquier otra medida puramente coyuntural también fracasarán en la pretensión preventiva. Mientras no se ataque el origen del problema, con medidas pertinentes y no simbólicas, el problema seguirá en aumento, con el nefasto mensaje, incluso en términos de prevención general y confianza en la administración de justicia, de que el Derecho penal no sirve.

Además, de aceptarse tal técnica legislativa tendríamos que llegar, so pena de discriminación negativa, a consagrar tipos penales en la parte especial del código, en consideración a, por lo menos, todos los colectivos reconocidos como tales, como las mujeres, los homosexuales, los hombres, los transexuales, los indígenas, los de raza distinta a la que se cree dominante, etc., y así consagrar casuísticamente tantos tipos penales como diferencias, no solo de homicidio sino en cualquiera que en el trasfondo pueda estar la diferencia como elemento subjetivo del tipo. De hecho, no encuentro diferencia alguna entre el homicidio de una mujer por serlo y el de un homosexual por su condición, salvo que lo que haga la diferencia no sea la víctima sino su victimario.

En este sentido, para poner solo un ejemplo con un grupo poblacional que puede resultar discriminado negativamente con la discriminación positiva a favor de otro, se privilegiaría punitivamente el homicidio con víctima hombre (no se nos olvide que los hombres también son víctimas de violencia sexual, con ocasión del conflicto por ejemplo, y que la criminalidad oculta en este sector de la población puede ser más alta que en el de las mujeres, pues mientras que en ellas cada día se visualiza mas, en ellos suele ser más vergonzante y por ende invisible), porque mientras se reprocha con mayor ahínco el feminicidio, no tiene explicación el menor rechazo de un homicidio en razón del género de la víctima que no es mujer.

Piénsese, para seguir con ejemplos, en el caso del hombre a quien se le causa la muerte en razón de su género y el delito es repudiado en menor medida a la que hubiera tenido de ser mujer; o en el homicidio del transexual a quien se identifica como mujer y resulta ser hombre o al que se identifica como hombre y se le causa la muerte por tal condición y resulta ser mujer. ¿Tiene sentido la discriminación penal para estos casos? ¿Lo tiene para cualquier caso?

La propuesta entonces estaría dirigida al proceso legislativo guiado por una política criminal coherente con un Derecho penal de la libertad, que busque la solución por fuera de la ley penal; no acudir al Derecho penal como prima ratio sino luego de haber implementado todas las medidas distintas a él; habiendo sustentado empíricamente la ineficacia de la ley existente y la eficacia de la que se propone; solo para los casos en que resulte imposible evitar el tratamiento penitenciario y con tipos penales cerrados pero respetuosos de las diferencias, lo que se puede lograr con una agravante que abarque todos los casos sin hacer distinciones odiosas. Podría ser, como ejercicio inicial para el homicidio, las lesiones, el acceso carnal violento o 
cualquier cuya comisión pueda estar motivada en las diferencias, con un agravante genérico (que opere para todos los delitos en que la lógica jurídica lo permita) consistente en el motivo originado en la diferencia o en la esencia de la víctima (de hecho basta el numeral $3^{\circ}$ de 58 del C.P.), pero sin tipificar cada uno de los que se antojen necesarios, que no solo desarticulan el estatuto penal, sino que terminan discriminando negativamente.

Sobra decir que los delitos que se fundan en diferencias fisiológicas no son eventos de discriminación positiva aun cuando se presenten como tales a favor de un determinado colectivo de personas, como la planificación o esterilización forzada (que puede también darse en los hombres), el aborto forzado, el embarazo forzado, la inseminación forzada, la castración, la mutilación genital, el matrimonio forzado, etc.

Recordemos que los códigos penales no solo califican al sujeto pasivo de la conducta, también en ocasiones califica al activo y en algunos eventos tal calificación se da por el género ${ }^{22}$. Por supuesto no se pretende traer esta temática para tipificar delitos propios de las mujeres; por el contrario, el llamado es a la reflexión sobre aquellos delitos cuya consagración puede resultar siendo una afrenta a la dignidad y libertad de la mujer, ellos sí una discriminación, como lo son el aborto y ciertas acciones previstas como delitos contra la libertad sexual o la familia, en los que se discrimina negativamente a la mujer violentando su libertad, su intimidad, su dignidad, su independencia y autonomía, cuando el Derecho penal se impone sobre ella con sanciones que anulan la autonomía del $\operatorname{ser}^{23}$.

\section{Derecho procesal y género}

Digamos que frente al desarrollo del proceso penal en Colombia se hacen innegables las dificultades -los términos, el acceso, el represamiento y la congestión judicial, para mencionar solo algunos- pero que obviamente no son un asunto que tenga que ver con la calidad o el género de la víctima, en tanto son asunto que nos afectan a todos.

Sin embargo, sí me parece que por lo menos en dos asuntos el Derecho procesal debe hacer particulares consideraciones de género:

En primer lugar, en la consagración de normas que consagra el Derecho penal -no en pocas ocasiones en nuestro país-con un abusivo paternalismo que bajo la excusa de prevenir los ilícitos de género restringen los derechos de las mujeres, particular-

22 Ver: Juliano, Dolores, Las mujeres y los delitos en Género, Violencia y Derecho, Ed. Del Puerto, Buenos Aires, Argentina, 2009.

23 Comisión Asesora de Política Criminal, Informe Final. Diagnósticos y Propuesta de Lineamientos de política criminal para el Estado colombiano, Ministerio de Justicia y el Derecho Colombia, Agencia Presidencial de Cooperación Internacional de Colombia APC, Unión Europea, Bogotá, junio de 2012, p. 74 . 
mente su libertad y dignidad, cuando no de los demás sujetos procesales. Ejemplos de estas normas son aquellas que consagran investigaciones de oficio en asuntos disponibles o de interés fundamentalmente particular, la prohibición de desistimiento en asunto en que puede resultar preferible o menos dañoso para la mujer víctima, la prohibición de libertad o sustitutos de la detención en atención a la calidad del delito o de la víctima, la limitación en el Derecho penal premial, en la aplicación de la oportunidad, terminaciones anticipadas, etc., que además lesionan la igualdad; por mencionar solo algunos.

Por otro lado, en segundo lugar, debo resaltar que, aunque el acceso a la justicia debe ser procurado en condiciones de dignidad para cualquier persona usuaria del sistema, ello no excluye el reconocimiento de sus diferencias y sus particularidades y, por ende, la implementación de políticas públicas que garanticen su respeto.

Se reconocen particularidades humanas que hacen al sujeto realmente distinto de los demás (por ejemplo, a la minusvalía, la sordomudez, la minoría de edad, la extranjería) que imponen el tratamiento especial por tal calidad pero que no constituyen discriminación positiva, como quedó dicho arriba.

Pero las que realmente interesan son aquellas particularidades que no hacen distintos a los sujetos, pero que imponen políticas o tratamientos distintos. Dentro de ellos se encuentra la preparación de funcionarios para el digno y correcto manejo de la diligencia atendiendo la condición de la persona que accede a la justicia. Un buen ejemplo es el establecimiento de medidas de protección para las mujeres víctimas de violencia sexual con ocasión del conflicto armado consagradas en la Ley 1719 de 2014 (miembros del comité con experiencia, registro unificado de violencia contra la mujer). Medidas como estas que se consagran para un sector particular de la población, no deberían ser exclusivas de uno solo de ellos, sino que deben existir para todos los grupos en los que sus miembros posean calidades que ameriten o requieran una atención especial.

Debe decirse, manteniendo la coherencia de lo hasta aquí dicho y propuesto, que realmente solo el primero de los asuntos inmediatamente traídos aquí -el del paternalismo- se relaciona con el género en tanto que el que se refiere al digno acceso a la justicia es general y para todos los usuarios, pues no soportaría un juicio de constitucionalidad el establecimiento de medidas, bajo el parapeto de la acción afirmativa o de la discriminación positiva, que procuren el trato digno de las mujeres solamente.

\section{Derecho penitenciario y género}

Aquí también se debe distinguir entre diferencias sexual y diferencia surgida por el género. Por ello mismo me parece que no es posible afirmar que aquellas mejores condiciones motivadas u originadas en las diferencias sexuales son una acción afirmativa a favor del beneficiario. A nadie, por ejemplo, se le ocurriría calificar como 
discriminación positiva, la contratación de un médico ginecólogo para la cárcel de mujeres o uno especializado en la próstata para la de hombres.

Me surge la pregunta entonces, si es posible tener un trato diferencial en la ejecución de la sentencia, obviamente desde la perspectiva de género. Y eso precisamente me ha generado una gran curiosidad por un fenómeno que me llama poderosamente la atención: Encuentro que aun cuando el Derecho penal de género, por lo menos en el deber ser, tiene en su mira la protección de la mujer, es poco o nada lo que se propone en relación con la prevención especial del victimario, como si lo que interesara solo fuera el carácter retributivo de la pena en aras de una justicia retaliativa y de pronto reivindicativa y, por ende, solo simbólica.

Me explico, la idea es que la pena prevenga, ya de manera general o de manera especial y ya de manera positiva como de manera negativa. Así las cosas, la pena que se impone a quien es autor del delito de violencia de género, por ejemplo, el feminicidio, debe procurar que el sujeto responsable no incurra nuevamente en el delito, con mayor razón si se tiene en cuenta que la pena no es perpetua. Por ello y no por otra razón no encuentra justificación que leyes especiales que discriminan favorablemente a la mujer, lo hagan sin consideración a lo que es mejor para la mujer misma desde el tratamiento penitenciario del victimario en aras de prevención especial y no desde la pena en aras de retribución. Para hacer el análisis de cómo se motiva la ley, basta detenerse en el hecho de que el aumento de la pena de la ley del feminicidio solo es eso, un aumento y no, como debería ser, la consagración de un tratamiento distinto y diferenciado para los responsables de delitos contra las mujeres en aras de la protección, en términos de prevención, de ellas mismas.

No he visto en quienes promueven el Derecho penal de género diferenciado, más que propuestas que marcan negativamente la diferencia (aumentos de pena, negación de beneficios o rebajas, etc.) pero no las que pretenden que no exista, como mejores tratamientos penitenciarios para los hombres en busca de resocialización que redunda en seguridad de género.

\section{CONCLUSIONES}

Creo que el Derecho penal, aun reconociéndole una función simbólica, no es un mecanismo adecuado para reconocer desigualdades injustas.

Desde luego no es idónea, y en mi sentir es incorrecta, la tipificación de conductas especiales para cada uno de los colectivos reconocidos, con lo que se desarticula el Código Penal haciendo más difícil cada día el proceso de adecuación típica. Recuérdese que cuando el tipo distingue y no incluye algo respecto de él debe entenderse el deseo del legislador de no incluirlo. 
Las consideraciones de género no inciden en beneficio de las mujeres sino en beneficio de todos aquellos a favor de quienes se consagren independientemente de su género, su identidad, su condición sexual, etc.; si se quiere: el Derecho penal debe ser neutro, de manera que cualquier consideración ha de hacerse en abstracto, por ejemplo, con agravantes que se redacten con algo así como "cuando se cometa con ocasión de una diferencia”. En este sentido no se debe discriminar negativamente al hombre por razones cuantitativas o del sexo de la mayoría de las víctimas, como si por ser menos los hombres que las mujeres los agredidos el hecho merezca un reproche menor. Según la estadística, por ejemplo, la violencia intrafamiliar y sexual se concentra mayoritariamente en las mujeres, pero el número de hombres víctima no es nada despreciable ${ }^{24}$. ¿Acaso esos casos son razonablemente discriminados negativamente o justifican una discriminación tolerada como para que haya agravante por el género mujer o feminicidio, pero en el caso de la víctima hombre por serlo es simplemente un homicidio? En este sentido resulta cuestionable la filosofía de la Ley 1761 de 2015, por lo menos en lo que hace a la consagración del feminicidio y en la consideración de medidas de política pública claramente diferencias a favor de la mujer, cuando cualquier otro ser humano con identidad de género distinta también es víctima de tal violencia, aunque en cifras menores respecto de las víctimas mujeres -si bien no se conocen en su verdadera dimensión- pero no por ello es un fenómeno despreciable en aras de una determinada discriminación positiva.

No es lo mismo la diferencia de género (igualable) que la diferencia de sexo (natural e inigualable). Tampoco la violencia sexual es igual a la violencia de género. En este último sentido debe rechazarse cualquier tipo de agresión sexual por serlo, pero no en razón del género, sin perjuicio de que concurran.

Algunas, si no todas las discriminaciones positivas (tema en sobre el cual no está cerrado el debate y sobre el cual no se debe cerrar) no solo son una discriminación negativa, diríamos colateral, indeseable del otro sector de la población que se tiene como históricamente privilegiado, sino que en sí misma, en el tema que nos ocupa, constituye una discriminación paternalista y por ello negativa de la mujer. A más de ello, la Constitución no distingue la discriminación cuando la prohíbe.

También me preocupa que la imposición legal de patrones culturales y comportamentales así como de consecuencias judiciales para las víctimas (ejemplo el carácter de delitos de oficio en todos los casos o la prohibición de desistimiento) terminen lesionando la autonomía de las personas violentadas, muchas de las cuales se ven compelidas a soportar las decisiones legislativas de otros o de grupos que se abrogan derechos de todos, que más bien con ello le arrebatan su libertad como esencia de

24 Corporación Sisma Mujer. Comportamiento de las violencias contra las niñas y mujeres en Colombia a partir del Informe Forensis del Instituto Colombiano de Medicina Legal, 18 de julio de 2017. 
dignidad, por ejemplo incidiendo en su libertad de decisión respecto del “....modo de gestionar su relación de pareja que en algún momento ha actuado de forma violenta" 25 .

La violencia de género no es exclusiva de un género. Es preocupante que en ocasiones el problema del género en el Derecho penal se demande no por la calidad de la víctima sino por la del victimario, como en la definición que de homicidio hace Diana Rusell citada por Arocena y Cesano ${ }^{26}$ o la definición que de violencia de género comparten los mismos de Alonso Alamo ${ }^{27}$. Ello significa que no es de recibo la discriminación por el género del autor del delito (por ejemplo con la calificación del sujeto activo como elemento del tipo), en tanto violencia de género es un asunto que cometen tanto hombres contra mujeres y por ende no puede depender del género del victimario; como no lo es el establecimiento de consecuencias procesales negativas para el victimario (por ejemplo la exclusión de beneficios judiciales, la imposibilidad de acudir al Derecho penal premial, la prohibición de desistimiento) sin consideración a las decisiones procesales de la víctima, por ejemplo en un contexto de pareja o familia.

Es importante que la política criminal, y con ella quienes quieren y logran medidas punitivas contra quien sea sujeto activo de la violencia de género (por ejemplo la Ley 1761 del 6 de julio de 2015 que derogó el agravante del numeral 11 del artículo 104 del Código Penal que a su vez tipificó la agravante del homicidio contra mujer por serlo), se preocupen también por ajustar el tratamiento penitenciario del agresor en aras de resocialización (que redunda en la integridad de la mujer) y no solo en el aumento de la pena como retribución y en la excusión de beneficios, que de paso discrimina.

Se propone no acudir en exclusiva al Derecho penal del que además su efectividad siempre ha estado en duda, nutriendo la nefasta expectativa, que ahora se promueve, según la cual los jueces y el Derecho penal son los responsables de la solución a todos los problemas sociales. En efecto, el problema del género y de la violencia de género no encarna un problema legal, por lo que la solución no está en la ley. Se trata de un problema social y los problemas sociales deben tener solución por fuera del Derecho, posiblemente contando con su aporte, pero no en exclusiva, porque eso sería, y es, puro Derecho penal simbólico, más perjudicial que la anomia misma.

La discriminación a favor de la mujer termina discriminando otros grupos poblacionales cuyas lesiones no se sancionan, por no quedar incluidos en el tipo penal de género.

25 LAURenZo, PATricia, La Violencia de género en el derecho penal: un ejemplo de paternalismo punitivo en Género, Violencia y Derecho, Ed. Del Puerto, Buenos Aires, Argentina, 2009 p. 268.

26 Arocena, Gustavo y Cesano, José, El Delito de Feminicidio. Aspectos político criminales y análisis dogmático jurídico, Ed. BdeF, Montevideo, Uruguay 2013, p. 15.

27 Ídem, p. 20. 
Piénsese por ejemplo en los homicidios en razón del género masculino o en razón de la homosexualidad que, sobra decirlo, no caben en el tipo penal de feminicidio.

La discriminación positiva para la mujer desde el tipo penal, trae problemas serios en el momento judicial. Baste preguntarse qué podrá hacer la justicia, con justicia, en casos en que el homicidio se cometa en un hombre que tiene -y por tenerlaidentidad con el género femenino o el que se cometa en quien se cree mujer por su apariencia y se realice por el género mujer sin serlo. Cualquier respuesta respetuosa del principio de legalidad, en estos como en muchos casos, resulta discriminatoria.

En ese mismo sentido habría que valorar negativamente a aquellos que dan por satisfecha su tarea promoviendo el populismo punitivo, muy conveniente en términos electorales, pero muy perjudicial en términos de solución y de respeto.

Aun en el evento en que se acepte la discriminación positiva de la mujer, surge la pregunta "hasta cuándo" tolerar la discriminación, resaltando desde ya que resulta inaceptable para un Derecho penal gobernado por principios como el de legalidad, igualdad y seguridad jurídica, la respuesta "hasta que sea necesario" 28 , como lo reconoce, con buen criterio, nuestra Corte Constitucional al reclamar la temporalidad de las medidas de esta naturaleza ${ }^{29}$. Preocupa en particular el hecho de que, si las medidas aceptadas de discriminación positiva visibilizan la problemática, lo seguirán haciendo indefinidamente, ocultando la demás y discriminando negativamente otras víctimas y por ende tratando de dar justificación al tratamiento diferencial cuando no se justifica. Desde luego no pretendo afirmar que está mal visibilizar la violencia de género, lo que pretendo es poner de manifiesto el yerro en que se incurre cuando a través de aparentes acciones afirmativas termina ocultándose parte de la violencia.

Resulta preocupante que la justificación de la penalización paternalista que discrimina positivamente a la mujer sea la dominación histórica del hombre en abstracto. No resulta ajustado a la Constitución ni razonable, en el marco de un Derecho penal de acto, el mayor reproche a un sujeto por lo que históricamente han hecho otros.

Se debe respetar la diferencia inigualable entre los seres humanos y rechazar la desigualdad fundada en aquello en que no genera diferencias, por lo que deben promoverse las medidas necesarias para que estas no existan. No por ello resulta plausible la implementación de medidas simbólicas que no son más que eso, que también envían, y tal vez en mayor medida, un mensaje que resalta y retiñe la desigualdad contra la que se lucha.

28 Recuérdese la sentencia C-371 de 2000 que recomienda la temporalidad de las acciones afirmativas.

29 Corte Constitucional Colombiana, Sentencia C-371 de 2000. 


\section{BIBLIOGRAFÍA}

Arocena, Gustavo y Cesano, José, El Delito de Feminicidio. Aspectos político criminales y análisis dogmático jurídico, Ed. BdeF, Montevideo, Uruguay, 2013.

Cardona Gómez, Gloria del Pilar; Franco Cian, Laura; Aldana Nope, Adriana CARolina, Los rostros de las mujeres víctimas del conflicto armado en Colombia: diferentes formas de violencia de género, Universidad El Bosque Colombia. En: Informe Forensis 2016, Instituto Colombiano de Medicina Legal, Grupo Centro de referencia Nacional sobre la violencia, primera edición, Bogotá, D.C., junio, 2017.

Comisión Asesora de Política Criminal, Informe Final. Diagnósticos y Propuesta de Lineamientos de política criminal para el Estado colombiano, Ministerio de Justicia y el Derecho Colombia. Agencia Presidencial de Cooperación Internacional de Colombia APC. Unión Europea, Bogotá, junio de 2012.

CONSTITUCión POLÍTICA DE COLOMBIA, [Const.] (1991) Artículo 13 [Título II].

Convención para Prevenir, Sancionar y ERradicar la Violencia contra la MUJER, Adoptada por Colombia en la Ley 248 de 1995.

Corporación Sisma Mujer, Comportamiento de las violencias contra las niñas y mujeres en Colombia a partir del Informe Forensis del Instituto Colombiano de Medicina Legal, 18 de julio de 2017.

Corte Constitucional Colombiana, (09 de febrero de 2000), Sentencia C 112 de 2000, M.P.: Alejandro Martínez Caballero.

Corte Constitucional Colombiana, (09 de septiembre de 1998), Sentencia C 481 de 1998 M.P.: Alejandro Martínez Caballero.

Corte Constitucional Colombiana, (15 de septiembre de 1994), Sentencias C 098 y 410 de 1994, M.P.: Carlos Gaviria Díaz.

Corte Constitucional Colombiana, (29 de marzo del 2000) Sentencia C-371 de 2000, M.P.: CARLos Gaviria Díaz.

COMITÉ PARA LA ELIMINACIÓN DE LA DISCRIMINACIÓN CONTRA LA MUJER (CEDAW, por sus siglas en inglés), 1979. Adoptada por Colombia en la Ley 51 de 1981.

Estatuto de Roma de la Corte Penal Internacional - Naciones Unidas, 1998. Adoptado por Colombia en la Ley 742 de 2002. 
InForme Forensis 2016, "Instituto Colombiano de Medicina Legal" Grupo Centro de referencia Nacional sobre la violencia Primera edición. Bogotá, D.C., junio, 2017.

Juliano, Dolores, Las mujeres y los delitos, en Género, Violencia y Derecho, Ed. Del Puerto, Buenos Aires, Argentina, 2009.

Laurenzo, Patricia, La Violencia de género en el Derecho penal: un ejemplo de paternalismo punitivo, en Género, Violencia y Derecho, Ed. Del Puerto, Buenos Aires, Argentina, 2009.

MAQUEDA, MARÍA LUISA, ¿Es la estrategia penal una solución a la violencia contra las mujeres? Algunas respuestas desde un discurso feminista crítico, Ed. Del Puerto, Buenos Aires, Argentina, 2009. 